IZA DP No. 6428

The Gender Wage Gap by Education in Italy

Chiara Mussida

Matteo Picchio

March 2012 


\title{
The Gender Wage Gap by Education in Italy
}

\author{
Chiara Mussida \\ Università Cattolica del Sacro Cuore, Piacenza \\ Matteo Picchio \\ Sherppa, Ghent University, \\ CentER, ReflecT, Tilburg University and IZA
}

Discussion Paper No. 6428

March 2012

\author{
IZA \\ P.O. Box 7240 \\ 53072 Bonn \\ Germany \\ Phone: +49-228-3894-0 \\ Fax: +49-228-3894-180 \\ E-mail: iza@iza.org
}

Any opinions expressed here are those of the author(s) and not those of IZA. Research published in this series may include views on policy, but the institute itself takes no institutional policy positions.

The Institute for the Study of Labor (IZA) in Bonn is a local and virtual international research center and a place of communication between science, politics and business. IZA is an independent nonprofit organization supported by Deutsche Post Foundation. The center is associated with the University of Bonn and offers a stimulating research environment through its international network, workshops and conferences, data service, project support, research visits and doctoral program. IZA engages in (i) original and internationally competitive research in all fields of labor economics, (ii) development of policy concepts, and (iii) dissemination of research results and concepts to the interested public.

IZA Discussion Papers often represent preliminary work and are circulated to encourage discussion. Citation of such a paper should account for its provisional character. A revised version may be available directly from the author. 
IZA Discussion Paper No. 6428

March 2012

\section{ABSTRACT}

\section{The Gender Wage Gap by Education in Italy*}

This paper studies the gender wage gap by educational attainment in Italy using the 19942001 ECHP data. We estimate wage distributions in the presence of covariates and sample selection separately for highly and low educated men and women. Then, we decompose the gender wage gap across all the wage distribution and isolate the part due to gender differences in the remunerations of the similar characteristics. We find that women are penalized especially if low educated. When we control for sample selection induced by unobservables, the penalties for low educated women become even larger, above all at the bottom of the wage distribution.

JEL Classification: $\quad \mathrm{C} 21, \mathrm{C} 41, \mathrm{~J} 16, \mathrm{~J} 31, \mathrm{~J} 71$

Keywords: gender wage gap, education, counterfactual distributions, decompositions, hazard function

Corresponding author:

Matteo Picchio

Sherppa

Ghent University

Tweekerkenstraat 2

9000 Gent

Belgium

E-mail: matteo.picchio@ugent.be

\footnotetext{
Data from the European Community Household Panel Survey 1994-2001 are used with the permission of Eurostat (contract ECHP/2012/02). The results and conclusions are those of the authors and not those of Eurostat, the European Commission, or any of the authorities whose data have been used. Chiara Mussida acknowledges financial support from Fondazione di Piacenza e Vigevano. Matteo Picchio acknowledges financial support from Fonds Wetenschappelijk Onderzoek (FWO).
} 


\section{Introduction}

Since the 1950s, gender equality has been widely accepted as a socially and economically important goal in most industrialized countries. It is not only a moral value and an important policy to enable men and women to maximize their potential. It might also be a tool for economic and welfare growth, as gender equality means utilization of the full productive potential of the labour force.

Over the last decades, significant progress has been made in reducing labour market gender inequalities in industrialized countries, but they are still persistent in most of them. Several studies have shown that women suffer disadvantages and penalties in terms of employment prospects, career promotions, and wages. For example, the meta-analysis conducted by Weichselbaumer and Winter-Ebmer (2005) reveals that in industrialized countries the gender pay gap decreased from $65 \%$ in the 1960 s to $30 \%$ in the 1990 s. This evolution is attributable to women's increased level of education and work experience. Other studies, such as Blau and Khan (2006) and Kolesnikova and Liu (2011) for the US, point out that differences in educational attainment, work experience, and occupational choice significantly contribute to the gender wage gap and to its time trend. However, if one nets out the contribution of gender differences in characteristics, the gender wage gap has been roughly constant over the decades and around $25 \%$. $^{1}$

In economics a large body of the empirical studies on labour market gender inequalities focus on wage gaps. As a matter of fact, the wage is a relevant indicator of access to resources and opportunities. The main issue of this empirical literature is often to understand whether and to what extent the gender pay gap is due to gender differences in the distribution of personal characteristics or in the remuneration of the same characteristics. In order to design effective policies in tackling gender inequalities, it is indeed fundamental to understand the contribution of each component.

Inspired by the analysis in de la Rica et al. (2008) and Addabbo and Favaro (2011) on Spanish and Italian gender wage gaps by educational attainment, we analyse gender wage gaps in Italy at different educational levels. Education might play an important role in shaping the gender pay gap. The European Commission (2005) indeed reports that education is the most important observed characteristic explaining the level of wage inequality between men and women. We contribute to the existing empirical literature on gender wage gap by documenting the role played in Italy by sample selection in shaping the profile of the gender wage gap components across all the quantiles of the wage distribution at different

\footnotetext{
${ }^{1}$ See Azmat et al. (2006) for an analysis of gender gaps in unemployment, employment-to-unemployment flows, and unemployment-to-employment flows in OECD countries. See Pekkarinen and Vartiainen (2006) and the studies cited in this article for analyses on the role of gender in promotions.
} 
educational levels.

Addabbo and Favaro (2011) show that in Italy the wage penalty of full-time women is larger at low educational attainments: it is about $11.2 \%$ for highly educated women and $14.5 \%$ for low educated women at the median of the wage distribution. However, if gender differences in the nonrandom selection into full-time work vary with the educational attainmanent, this finding might just be a statistical artefact. When the effect of sample selection is netted out, the higher gender wage penalty for low educated women could: i) disappear if highly educated women are more positively selected into the full-time workforce than low educated women, i.e. those highly educated women who would get the lowest returns from work are less likely to work full-time; ii) become even larger if low educated women are more positively selected into the full-time workforce than highly educated women.

Previous studies notice that in countries like Italy, where the gender gap in employment rates is relevant, it is important to control for gender differences in the selection rule into the workforce. When the estimation of the gender wage gap is corrected for gender differences in workforce participation, the gender wage gap widens and reaches the same levels as the ones in countries with smaller gender gaps in employment rates (Olivetti and Petrongolo, 2008; Picchio and Mussida, 2011). Similarly, Albrecht et al. (2009) find that in the Netherlands wage penalties for women increase across all the wage distribution once nonrandom selection into full-time employment is controlled for.

As Addabbo and Favaro (2011), we use data from the European Community Household Panel (ECHP). The empirical analysis is based on the technique proposed by Picchio and Mussida (2011) to estimate wage distributions in the presence of covariates and sample selection and on simulation algorithms to derive counterfactual distributions and decompose the gender wage gap. The longitudinal dimension of the ECHP is exploited to avoid exclusion restrictions in identifying wage distributions in the presence of covariates and sample selection. We show that in Italy gender wage penalties widen for low educated women when corrected for sample selection, especially at bottom jobs. They are instead left unchanged for highly educated women. Low educated women are therefore more positively selected into the full-time workforce than men and than highly educated women. When comparing gender wage gaps across educational attainments in Italy, it is therefore important to net out the effect induced by different sample compositions to avoid the underestimation of the role played by education in shaping labour market inequalities.

The paper proceeds as follows. Section 2 describes the data and the sample. Section 3 presents the methodology to estimate wage distributions in the presence of covariates and sample selection and reports estimation results. In Section 4, we simulate the model to decompose the gender wage gap in the parts due to gender differences in individual characteristics and in the remuneration of similar characteristics across all quantiles of the wage 
distribution. Section 5 concludes.

\section{Data and Sample}

The empirical analysis is based on a sample extracted from the 1994-2001 waves of the ECHP. $^{2}$ We exclude from our sample individuals younger than 25 years and older than 64 years to avoid to get mixed with formal education enrolment issues. We drop individuals who are in the army, self-employed, inactive, or with missing values in the variables used in the econometric analysis. Finally, in order to avoid outliers' or measurement errors problems, we exclude from the sample individuals lying in the first or last percentile of the wage or working hours distributions.

Considering both employed and the non-employed, 38,060 female observations and 30,796 male observations remain over the period 1994-2001. We have 9,605 female fulltime employees and 19,616 male full-time employees. The definition of full-time employment is based on working hours. Employees are considered as full-time workers if they declare to work 35 hours or more per week. Among highly educated people the participation to full-time work is higher and shows lower gender disparities: $70.8 \%$ (37.9\%) of highly educated (wo)men work full-time against 57.6\% (15.6\%) of low educated (wo)men.

The sample and the econometric analysis are split by gender but also by educational attainment. We distinguish between low and highly educated people. The definition of high and low education follows Addabbo and Favaro (2011): we split the sample using as a threshold the compulsory educational level. ${ }^{3}$ Given that information on education is provided in the ECHP according to the International Standard Classification of Education (ISCED), we define as low educated those individuals with an ISCED level between 0 and 2 and as highly educated those individuals with an ISCED level between 3 and 7.

The wage variable is the gross hourly wage. It is computed starting from information about the gross monthly wage and the weekly working hours. ${ }^{4}$ The gross hourly wages are deflated to 1995 constant prices. ${ }^{5}$ Figure 1 plots the kernel estimate of the wage density by gender and educational levels. The distance between men and women's distribution densities represents the extent of the raw gap. In both educational groups, the differential is

\footnotetext{
${ }^{2}$ More information about the ECHP is available in Internet at http://epp.eurostat.ec.europa.eu/portal/page/portal/eurostat/home.

${ }^{3}$ See Addabbo and Favaro (2011) for more details about the Italian educational system and compulsory education.

${ }^{4}$ The gross hourly wage is obtained by taking the ratio between the gross monthly wage, variable PI211MG, and the number of hours worked per week - variable PE005 - times 4.35, the average number of weeks in a month.

${ }^{5}$ The deflator is the Consumer Price Index (CPI), gathered by ISTAT.
} 
Figure 1: Kernel Density Estimates of Full-Time Gross Hourly Wages by Gender and Education
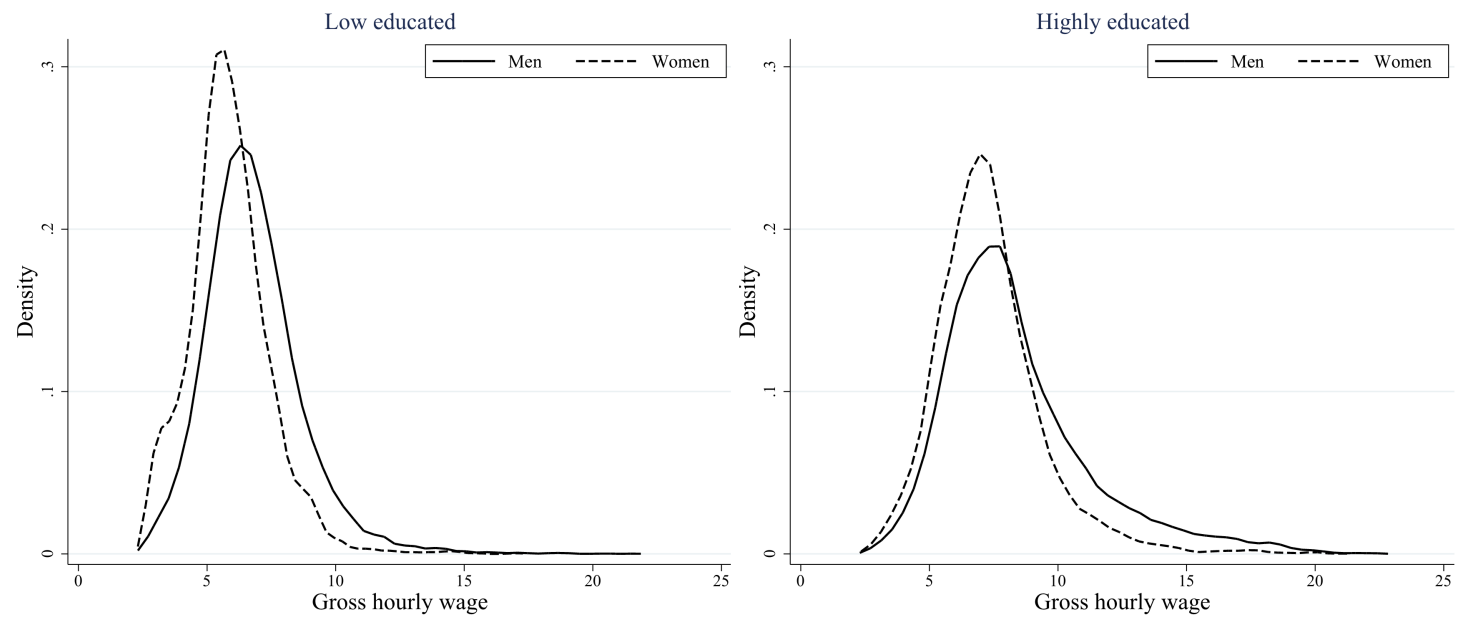

in favour of men, especially if low educated. Table 1 reports raw statistics about the gender wage gap. On average, both low and highly educated women have lower hourly wages: the average raw gender wage gap is equal to $0.150 \mathrm{log}$ points for low educated women and to $0.137 \mathrm{log}$ points for highly educated women. However, the profile of the raw gender wage gap across the wage distribution differs by education. Low educated women suffer a U-shaped wage penalty: the gender wage gap is the highest at the bottom of the wage distribution $(0.178 \log$ points $)$, it is the lowest at the 25 th percentile $(0.123$ log points $)$ and then it increases at the top of the distribution $(0.160 \log$ points at the 90 th percentile). The raw gender wage penalty is instead increasing across the whole wage distribution for highly educated workers: it goes from $0.066 \log$ points at the 10 th percentile to $0.229 \log$ points at the 90th percentile.

Table 1: Full-Time Raw Gender Wage Gap in Italy by Educational Attainment (in log points)

\begin{tabular}{lcc}
\hline \hline & Low educated & Highly educated \\
\hline Mean & .150 & .137 \\
$10^{\text {th }}$ percentile & .178 & .066 \\
$25^{\text {th }}$ percentile & .123 & .073 \\
$50^{\text {th }}$ percentile & .140 & .098 \\
$75^{\text {th }}$ percentile & .149 & .151 \\
$90^{\text {th }}$ percentile & .160 & .229 \\
\hline
\end{tabular}

Table 2 reports summary statistics of the covariates used to model wage distributions 
computed on the subsample of the full-time workers and disaggregated by gender and educational attainment. We use a set of variables that are often included in Mincerian models and that might capture differences in human capital (age and job tenure), in the local labour market (geographical area of residence), in the business cycle (time indicators), in job tasks (occupational indicators and type of contract), in firms (firm size and sector), and other individual characteristics (health and marital status).

Highly educated men earn on average more (gross hourly wage of $€ 8.4$ ) compared both to highly educated women $(€ 7.3)$ and to low educated of both genders, especially women. Low educated women indeed earn the lowest gross hourly wages (€5.8).

Low educated (wo)men working full-time are on average 42 (41) years old and older than highly educated ones (on average 39 years of age for men and 37 for women). The indicator of self-perceived health captures the effect of health status (perceived or subjective) on wages and propensity to work and highly educated workers are on average in better health conditions compared to low educated. The percentage of married men full-time workers is higher than married women, especially for low educated (80.6\% of low educated men fulltime workers is married against $68.9 \%$ of low educated women).

Highly educated women work more frequently as public employee $(51.3 \%)$ and into the service sector $(81.1 \%$ ) compared to both highly educated men and low educated men and women. The dummy variable for atypical jobs captures the impact of atypical contractual arrangements introduced and generalized by the 1997 labour market reform (Law No. 196/1997, “Treu Package") on wages. On average, low educated individuals of both genders are more frequently employed with atypical contracts than highly educated individuals.

Three indicators control for the geographical area of residence and split Italy in North, Centre, and South. Almost one half of the low educated women working full-time live in the North of Italy, while the others are equally distributed in the Centre and South. Men are instead more equally distributed across all the three geographical areas.

Since the job tenure is likely to affect wages, we control for it using four dummy indicators. On average, one half of men and women of both education attainments have a job tenure longer than 11 years.

In modelling wages we use a set of indicators for the type of occupation. They are likely to be very important: the segregation of women into certain types of occupation might indeed account for a significant part of the pay gap, as it is shown for instance in Bayard et al. (2003) and Addabbo and Favaro (2011). In our sample, low educated full-time workers are largely concentrated in blue-collar occupations and craft and related trades jobs. Highly educated women are more likely than highly educated men to belong to the top three occupational categories: around $13.1 \%$ of women work as legislator, $18.4 \%$ as technician and associate professional, and more than one half are clerks $(50.4 \%)$. 
Table 2: Summary Statistics of the Covariates for Full-Time Workers by Gender and Education

\begin{tabular}{|c|c|c|c|c|c|c|c|c|}
\hline & \multicolumn{2}{|c|}{$\begin{array}{l}\text { Low educated } \\
\text { men }\end{array}$} & \multicolumn{2}{|c|}{$\begin{array}{l}\text { Low educated } \\
\text { women }\end{array}$} & \multicolumn{2}{|c|}{$\begin{array}{l}\text { Highly educated } \\
\text { men }\end{array}$} & \multicolumn{2}{|c|}{$\begin{array}{l}\text { Highly educated } \\
\text { women }\end{array}$} \\
\hline & Mean & S.D. & Mean & S.D. & Mean & S.D. & Mean & S.D. \\
\hline Gross hourly wage $(€)$ & 6.807 & 1.892 & 5.858 & 1.566 & 8.400 & 2.893 & 7.325 & 2.096 \\
\hline Age (years) & 42.338 & 9.929 & 41.543 & 9.573 & 39.593 & 8.785 & 37.541 & 8.276 \\
\hline Good health ${ }^{\S}$ & .677 & .468 & .636 & .481 & .767 & .423 & .737 & .440 \\
\hline Married & .806 & .395 & .689 & .463 & .743 & .437 & .668 & .471 \\
\hline Public employee & .285 & .451 & .270 & .444 & .390 & .488 & .513 & .500 \\
\hline Atypical job ${ }^{\dagger}$ & .256 & .436 & .267 & .442 & .193 & .395 & .189 & .391 \\
\hline Service sector & .457 & .498 & .544 & .498 & .631 & .483 & .811 & .392 \\
\hline \multicolumn{9}{|l|}{ Geographical area } \\
\hline North & .354 & .478 & .510 & .500 & .404 & .491 & .472 & .499 \\
\hline Centre & .246 & .430 & .246 & .431 & .265 & .441 & .237 & .425 \\
\hline South & .395 & .489 & .236 & .425 & .320 & .467 & .284 & .451 \\
\hline \multicolumn{9}{|l|}{ Job tenure in years } \\
\hline$[0,6)$ & .276 & .447 & .254 & .436 & .267 & .442 & .291 & .454 \\
\hline$[6,11)$ & .115 & .319 & .132 & .338 & .160 & .367 & .181 & .385 \\
\hline 11 or more & .536 & .499 & .507 & .500 & .504 & .500 & .431 & .495 \\
\hline Missing & .073 & .261 & .108 & .310 & .069 & .254 & .097 & .297 \\
\hline \multicolumn{9}{|l|}{ Occupation } \\
\hline Legislator, senior official, managers & .011 & .106 & .011 & .105 & .121 & .326 & .131 & .337 \\
\hline Technicians \& associate professionals & .038 & .192 & .074 & .262 & .176 & .381 & .184 & .388 \\
\hline Clerks & .098 & .297 & .176 & .381 & .331 & .471 & .504 & .500 \\
\hline Service \& sales workers & .086 & .281 & .141 & .348 & .067 & .249 & .076 & .264 \\
\hline Craft \& related trades workers & .347 & .476 & .239 & .427 & .127 & .333 & .027 & .162 \\
\hline Blue collar workers & .365 & .481 & .320 & .466 & .128 & .334 & .054 & .227 \\
\hline Unknown & .054 & .227 & .039 & .194 & .050 & .219 & .025 & .155 \\
\hline \multicolumn{9}{|l|}{ Firm size (number of employees) } \\
\hline$(0,4]$ & .200 & .400 & .167 & .373 & .105 & .307 & .153 & .360 \\
\hline$[5,19]$ & .249 & .432 & .255 & .436 & .190 & .392 & .188 & .391 \\
\hline$[20,99]$ & .203 & .403 & .225 & .417 & .234 & .424 & .220 & .414 \\
\hline$[100,499]$ & .114 & .318 & .125 & .331 & .155 & .362 & .131 & .338 \\
\hline 500 or more & .080 & .271 & .070 & .255 & .140 & .347 & .096 & .294 \\
\hline Not applicable/missing & .154 & .361 & .159 & .365 & .176 & .381 & .212 & .409 \\
\hline \multicolumn{9}{|l|}{ Year } \\
\hline 1994 & .151 & .358 & .146 & .353 & .132 & .339 & .116 & .320 \\
\hline 1995 & .144 & .351 & .147 & .354 & .133 & .339 & .126 & .332 \\
\hline 1996 & .138 & .345 & .144 & .352 & .134 & .341 & .134 & .341 \\
\hline 1997 & .122 & .328 & .124 & .330 & .124 & .330 & .125 & .330 \\
\hline 1998 & .122 & .328 & .123 & .328 & .126 & .332 & .126 & .331 \\
\hline 1999 & .110 & .313 & .115 & .319 & .121 & .326 & .123 & .329 \\
\hline 2000 & .109 & .312 & .106 & .308 & .118 & .323 & .127 & .333 \\
\hline 2001 & .102 & .303 & .095 & .293 & .111 & .315 & .123 & .329 \\
\hline \# of observations & \multicolumn{2}{|c|}{9,558} & \multicolumn{2}{|c|}{3,429} & \multicolumn{2}{|c|}{10,058} & \multicolumn{2}{|c|}{6,176} \\
\hline
\end{tabular}


Five indicator variables capture the firm size measured by the number of employees. More than one half of low educated full-time employees of both genders work in small and medium firms, whilst highly educated workers are more likely to work in medium-large firms.

Table 3 displays the descriptive statistics over the total population of the covariates used to model the selection into full-time employment. Around one third of highly educated women have kids younger than 12 years, whilst for low educated of both genders the percentages are lower (on average around 23\%). The number of household components is slightly higher for low educated compared to highly educated (on average 2.60 household members against 2.48). Finally, low educated men and women mainly live in the South of Italy (around 41\%), more than a third of the samples lives in the North and the remaining (around 23\%) in the Centre. The highly educated are instead more equally distributed across the geographical areas of residence.

Table 3: Summary Statistics of the Covariates for the Whole Sample by Gender and Education

\begin{tabular}{|c|c|c|c|c|c|c|c|c|}
\hline & \multicolumn{2}{|c|}{ Low educated men } & \multicolumn{2}{|c|}{ Low educated women } & \multicolumn{2}{|c|}{ "Highly educated men } & \multicolumn{2}{|c|}{ Highly educated women } \\
\hline & Mean & S.D. & Mean & S.D. & Mean & S.D. & Mean & S.D. \\
\hline Age (in years) & 45.997 & 11.674 & 46.839 & 10.916 & 40.123 & 10.349 & 38.717 & 9.633 \\
\hline Good health ${ }^{\S}$ & .591 & .492 & .518 & .500 & .759 & .428 & .727 & .446 \\
\hline Married & .781 & .414 & .827 & .378 & .675 & .468 & .712 & .453 \\
\hline Presence of kids $<12$ years & .234 & .423 & .231 & .422 & .283 & .450 & .331 & .471 \\
\hline \# of household components & 2.619 & 1.291 & 2.583 & 1.306 & 2.489 & 1.156 & 2.475 & 1.169 \\
\hline \multicolumn{9}{|l|}{ Geographical area } \\
\hline North & .347 & .476 & .346 & .476 & .368 & .482 & .382 & .486 \\
\hline Centre & .237 & .425 & .226 & .418 & .246 & .431 & .233 & .423 \\
\hline South & .410 & .492 & .420 & .494 & .373 & .484 & .374 & .484 \\
\hline \multicolumn{9}{|l|}{ Year } \\
\hline 1994 & .143 & .350 & .145 & .352 & .132 & .338 & .123 & .328 \\
\hline 1995 & .138 & .345 & .139 & .346 & .130 & .337 & .125 & .330 \\
\hline 1996 & .137 & .343 & .135 & .342 & .132 & .338 & .130 & .336 \\
\hline 1997 & .124 & .329 & .123 & .328 & .123 & .328 & .124 & .329 \\
\hline 1998 & .128 & .334 & .127 & .333 & .126 & .332 & .126 & .332 \\
\hline 1999 & .118 & .323 & .120 & .325 & .123 & .328 & .124 & .329 \\
\hline 2000 & .112 & .315 & .111 & .314 & .121 & .326 & .127 & .333 \\
\hline 2001 & .101 & .301 & .100 & .301 & .113 & .317 & .122 & .327 \\
\hline \# of observations & \multicolumn{2}{|c|}{16,592} & \multicolumn{2}{|c|}{21,923} & \multicolumn{2}{|c|}{14,204} & \multicolumn{2}{|c|}{16,137} \\
\hline
\end{tabular}

$\S$ "Good health" is a dummy indicator based on self-perceived health. It is equal to one if the individual declares that her health is in good or very good conditions. It is equal to zero, if the answer is fair, bad, or very bad conditions.

Even if exclusion restrictions are not needed for model identification, ${ }^{6}$ in the empirical model two variables, namely the presence of children younger than 12 years and the number

\footnotetext{
${ }^{6}$ Picchio and Mussida (2011) show that if panel data are available the model described below in Subsection 3.1 is uniquely identified without exclusion restrictions and parametric assumptions on the unobserved heterogeneity distribution.
} 
of household components, will explain the selection equation but will not enter the specification of the wage distributions. In Subsection 4.3 we assess the sensitivity of our findings by re-estimating the model without such exclusion restrictions.

\section{Estimation of Wage Distributions in the Presence of Co- variates and Sample Selection}

\subsection{The Econometric Model}

In this paper we exploit the method developed in Picchio and Mussida (2011) to estimate wage distributions in the presence of covariates and sample selection. ${ }^{7}$ As proposed by Donald et al. (2000), wage distributions can be modelled as if they were duration distributions in a hazard function framework. As the hazard function fully characterizes the corresponding distribution function, once we specify in a flexible way the hazard function, we have a flexible model for the corresponding distribution function. Moreover, we allow the wage hazard function to be determined by unobservables correlated to the unobservables determining the probability of full-time employment.

The estimation strategy boils down to the joint estimation of a binary choice model for the probability of full-time employment and of a wage hazard function correlated through unobserved determinants. In a panel data setting with $t=1, \ldots, T$, we adopt the following model framework,

$$
\begin{aligned}
y_{t} & =\mathbb{1}\left[z_{t}^{\prime} \delta+\varepsilon+u_{t}>0\right] \\
\theta\left(w_{t} \mid x_{t}, v\right) & =h_{t}\left(w_{t} \mid x_{t}\right) v=h^{0}\left(w_{t}\right) \exp \left[x_{t}^{\prime} \beta\left(w_{t}\right)\right] v
\end{aligned}
$$

where

- $y_{t}$ is the indicator variable denoting full-time employment status at time $t$ and $\mathbb{1}(\cdot)$ is the indicator function.

- $u_{t}$ is the idiosyncratic error term with Gompertz distribution. ${ }^{8}$

- $\theta$ is the wage hazard function.

\footnotetext{
${ }^{7}$ See also Mussida and Picchio (2011) for an empirical application of this method to evaluate changes over time of the gender wage gap.

${ }^{8}$ The conditional probability of full-time employment is therefore given by $\operatorname{Pr}\left(y_{t}=1 \mid z_{t}, \varepsilon\right)=$ $\exp \left[-\exp \left(z_{t}^{\prime} \delta+\varepsilon\right)\right]$. As a consequence, an increase in a variable with a positive coefficient results in the decrease in the probability of full-time employment. Subsection 4.3 checks the sensitivity of our results to alternative specifications of the distribution of $u_{t}$.
} 
- $z_{t}$ and $x_{t}$ are regressors explaining the employment probability and the wage distribution, respectively.

- $v$ and $\varepsilon$ are unobserved characteristics with joint distribution $G$.

- $h_{0}$ is the common wage baseline hazard function, which maps into a wage distribution function common to every unit that can then varies because of the impact of observed characteristics $x_{t}$ and unobserved characteristics $v$.

Picchio and Mussida (2011) show that this model is uniquely identified from panel data without exclusion restrictions and parametric assumptions on the structural wage hazard function $h_{t}$ and on the joint unobserved heterogeneity distribution $G$.

The wage hazard function in (2) is of mixed hazard type: the effect of the covariates is allowed to be different over the wage support. It is therefore more flexible than the mixed proportional hazard specification often used in duration analysis. We parametrically model $\exp \left[x_{t}^{\prime} \beta\left(w_{t}\right)\right]$ by splitting the wage support into 5 intervals, approximatively at each ventile of the wage distribution, and by allowing the set of parameter vectors to be different at each segment. The baseline wage hazard function $h^{0}\left(w_{t}\right)$ is assumed to be piecewise constant in order to avoid too strict parametric assumptions. ${ }^{9}$

The joint distribution of $v$ and $\varepsilon$ is approximated by a bivariate discrete distribution (Heckman and Singer, 1984) with a fixed number of support points, which have unknown locations and probability masses. We assume that $(v, \varepsilon)$ has four probability points with probability masses defined as follows:

$$
\begin{array}{ll}
p_{1} \equiv \operatorname{Pr}\left(v=v_{1}, \varepsilon=\varepsilon_{1}\right) & p_{2} \equiv \operatorname{Pr}\left(v=v_{2}, \varepsilon=\varepsilon_{1}\right) \\
p_{3} \equiv \operatorname{Pr}\left(v=v_{1}, \varepsilon=\varepsilon_{2}\right) & p_{4} \equiv \operatorname{Pr}\left(v=v_{2}, \varepsilon=\varepsilon_{2}\right)=1-p_{1}-p_{2}-p_{3} .
\end{array}
$$

In this case, we need to estimate four points of support and three probability masses. ${ }^{10}$ The

\footnotetext{
${ }^{9}$ We divided the wage support into $J=51$ intervals $I_{j}=\left[w_{j-1}, w_{j}\right)$, where $j=1, \ldots, J, w_{0}<w_{1}<$ $\ldots<w_{J}$, and $w_{J}=\infty$. $w_{J-1}$ corresponds to the last percentile of the unconditional wage distribution and $w_{0}$ to the minimum observed wage. We chose the width of the other 50 wage baseline segments by dividing the wage support between $w_{0}$ and $w_{J-1}$ in 50 equally spaced intervals. Our choice of the number of the baseline segments is somewhat arbitrary. Nevertheless, it returns narrow segment widths (between $€ 0.15$ for unconditional distribution of low educated women and $€ 0.31$ for the unconditional distribution of highly educated men) and it is thereby suitable for flexibly approximating all possible wage hazard functions. An ideal way to avoid any kind of parametric assumption when specifying of $h^{0}$ would be to estimate it nonparametrically using kernel-density estimation methods.

${ }^{10} v$ and $\varepsilon$ are independent if and only if $p_{1} p_{4}=p_{2} p_{3}$ (Van den Berg et al., 1994; Van den Berg and Lindeboom, 1998). This makes easy to test for sample selection. In Subsection 4.3, we test whether the results are sensitive to the chosen number of support points by increasing them.
} 
probabilities associated to the mass points are specified as logistic transforms:

$$
p_{m}=\frac{\exp \left(\lambda_{m}\right)}{\sum_{r=1}^{4} \exp \left(\lambda_{r}\right)} \quad \text { with } \quad \lambda_{4}=0 .
$$

We estimate the model by maximum likelihood. See Picchio and Mussida (2011) for details about the derivation of the likelihood function. The model is separately estimated by gender and educational attainment.

This estimator has some strengths but also some disadvantages. Firstly, like in quantile regression, the impact of covariates is allowed to vary across the wage support. However, we impose some parametric restrictions on this degree of variability in order to avoid overfitting biases. Secondly, if there were no observed and unobserved individual heterogeneity, the estimator would be just a Kaplan-Meier estimator of the wage hazard function, which translates into a histogram estimator of the wage density. Although the histogram estimator can approximate the shape of any density function, it is not free from difficulties, like the choice of the bin size. Lastly, our approach exploits panel data to control for nonrandom sample selection induced by unobserved heterogeneity without the need of exclusion restrictions. Nonetheless, we impose some parametric restrictions on the bivariate distribution of the unobserved heterogeneity for the sake of reducing the dimensionality of the estimation problem.

\subsection{Estimation Results}

\section{Probability of Working Full-Time}

Table 4 reports the estimated parameters of the Gompit selection equation into full-time employment by gender and educational attainment. The estimated coefficients are informative about the direction of the impact of each characteristic. A positive coefficient implies that an increase in the corresponding variable decreases the probability of full-time employment.

The full-time employment probability decreases with age and is lower in the Centre and in the South of Italy. People in good health are more likely to be full-time employed. The estimated parameters of family related covariates point out that in Italy the male breadwinner system prevails: (wo)men are more (less) likely to be in full-time employment if married and with children in the household. Both men and women are instead less likely to be in full-time employment when there are more members in the household. As a matter of fact, the number of people in the household might be a proxy for family earnings: the higher the family earnings, the lower the labour supply either at the intensive margin (hours of work) or at the extensive margin (labour market participation). 
Table 4: Estimation Results of the Gompit Selection Equation into Full-Time Employment by Gender and Education

\begin{tabular}{|c|c|c|c|c|c|c|c|c|c|c|c|c|}
\hline & \multicolumn{6}{|c|}{ Low educated } & \multicolumn{6}{|c|}{ Highly educated } \\
\hline & \multicolumn{3}{|c|}{ Men } & \multicolumn{3}{|c|}{ Women } & \multicolumn{3}{|c|}{ Men } & \multicolumn{3}{|c|}{ Women } \\
\hline & Coeff. & & S.E. & Coeff. & & S.E. & Coeff. & & S.E. & Coeff. & & S.E. \\
\hline Age (years) & .663 & $* * *$ & .018 & .353 & $* * *$ & .019 & .447 & $* * *$ & .023 & .122 & $* * *$ & .016 \\
\hline Good health & -.231 & $* * *$ & .033 & -.131 & $* * *$ & .035 & -.100 & $* *$ & .048 & -.002 & & .034 \\
\hline Married & -1.168 & $* * *$ & .044 & .318 & $* * *$ & .037 & -1.182 & $* * *$ & .057 & .119 & $* * *$ & .033 \\
\hline Presence kids $<12$ years & -.346 & $* * *$ & .045 & .223 & $* * *$ & .041 & -.452 & $* * *$ & .059 & .097 & $* * *$ & .035 \\
\hline \# household members & .062 & $* * *$ & .012 & .131 & $* * *$ & .012 & .120 & $* * *$ & .016 & .064 & $* * *$ & .011 \\
\hline \multicolumn{13}{|c|}{ Education-Reference: ISCED 5-7 } \\
\hline ISCED 3-4 & - & & - & - & & - & .473 & $* * *$ & .046 & -.159 & $* * *$ & .032 \\
\hline \multicolumn{13}{|c|}{ Area of residence - Reference: North } \\
\hline Centre & .205 & $* * *$ & .041 & .237 & $* * *$ & .043 & .166 & $* * *$ & .050 & .329 & $* * *$ & .038 \\
\hline South & .407 & $* * *$ & .037 & .400 & $* * *$ & .036 & .746 & $* * *$ & .045 & .311 & $* * *$ & .031 \\
\hline \multicolumn{13}{|c|}{ Time dummies - Reference: 2001} \\
\hline 1994 & -.623 & $* * *$ & .070 & -.061 & & .065 & -.193 & $* *$ & .086 & .146 & $* *$ & .058 \\
\hline 1995 & -.370 & $* * *$ & .076 & -.111 & & .070 & -.012 & & .091 & .045 & & .059 \\
\hline 1996 & -.222 & $* * *$ & .075 & -.061 & & .078 & .012 & & .092 & .055 & & .061 \\
\hline 1997 & -.030 & & .080 & -.023 & & .077 & .086 & & .099 & .181 & $* * *$ & .063 \\
\hline 1998 & .092 & & .076 & .060 & & .080 & .173 & $* *$ & .087 & .168 & $* * *$ & .063 \\
\hline 1999 & .254 & $* * *$ & .091 & -.039 & & .073 & .177 & $*$ & .093 & .199 & $* * *$ & .070 \\
\hline 2000 & .138 & & .092 & .056 & & .087 & .077 & & .106 & .141 & $*$ & .072 \\
\hline \multicolumn{13}{|c|}{ Unobserved heterogeneity support points and probability masses } \\
\hline$\varepsilon_{1}$ & -2.870 & $* * *$ & .090 & -2.939 & $* * *$ & .087 & .067 & & .094 & -2.882 & $* * *$ & .076 \\
\hline$\varepsilon_{2}$ & .168 & $* *$ & .083 & .075 & & .076 & -3.274 & $* * *$ & .105 & .322 & $* * *$ & .067 \\
\hline$\lambda_{1}$ & -.205 & $* * *$ & .064 & -.155 & & .105 & .780 & $* * *$ & .189 & .302 & $* * *$ & .076 \\
\hline$\lambda_{2}$ & .031 & & .078 & 1.664 & $* * *$ & .118 & 1.096 & $* * *$ & .144 & .129 & & .142 \\
\hline$\lambda_{3}$ & -.410 & $* * *$ & .099 & 1.351 & $* * *$ & .148 & 1.119 & $* * *$ & .140 & 1.076 & $* * *$ & .076 \\
\hline Log-likelihood & \multicolumn{3}{|c|}{$-37,239.8$} & \multicolumn{3}{|c|}{$-15,769.2$} & \multicolumn{3}{|c|}{$-36,092.8$} & \multicolumn{3}{|c|}{$-25,188.3$} \\
\hline$N$ & \multicolumn{3}{|c|}{3,500} & \multicolumn{3}{|c|}{4,160} & \multicolumn{3}{|c|}{3,019} & \multicolumn{3}{|c|}{3,246} \\
\hline$N T$ & \multicolumn{3}{|c|}{16,592} & \multicolumn{3}{|c|}{21,923} & \multicolumn{3}{|c|}{14,204} & \multicolumn{3}{|c|}{16,137} \\
\hline LR sample selection test & \multicolumn{3}{|c|}{$\chi^{2}(1)=14.0, p$-val. $=.000$} & \multicolumn{3}{|c|}{$\chi^{2}(1)=15.8, p$-val. $=.000$} & \multicolumn{3}{|c|}{$\chi^{2}(1)=25.2, p$-val. $=.000$} & \multicolumn{3}{|c|}{$\chi^{2}(1)=22.2, p$-val. $=.000$} \\
\hline
\end{tabular}

Notes: * Significant at the $10 \%$ level; ** significant at the $5 \%$ level; *** significant at the $1 \%$ level. 
Among highly educated people the ECHP survey allows us to distinguish between those with a tertiary education (ISCED 5-7) and those with a higher secondary education (ISCED 3-4). Men with tertiary education are more likely to be full-time employed, whereas for women we find the opposite effect. This gender difference might be explained by educational segregation. Even if institutional data show a growth in women's participation in post-secondary education (MIUR, 2006), there is evidence that in Italy women choose less "prestigious" and more stereotypical educational programmes, like literature, history, pedagogy, and pediatrics (Bettio and Verashchagina, 2008), have lower chances to enrol at post-tertiary education and, once in the labour market, they get lower wages compared to men with the same educational level (Gerber and Cheung, 2008; Triventi, 2010). Moreover, if jobs accessed through a post-secondary education degree requires more work commitment, it might be that women find it difficult to reconcile career and family care and they are therefore more likely to step back.

In 1997 a major labour market reform (Law No. 196/1997) introduced and generalized the use of atypical contracts in Italy, among which part-time jobs. In a period of quite stable economic growth, ${ }^{11}$ this might explain why both men and women are less likely to work full-time starting from 1997.

Finally, at the bottom of Table 4, we report the log-likelihood ratio (LR) test for nonrandom selection into full-time employment. For both men and women and for both highly and low educated individuals we cannot reject the null hypothesis of no sample selection.

\section{The Impact of Covariates on the Wage Hazard Function}

As mentioned in Subsection 3.1, the impact of covariates on the shape of the wage density functions is flexibly modelled. Analogously to quantile regression, the covariates can have different effects at different quantiles of the wage distribution. Hence, Tables 5 and 6 display the effect of the covariates at selected quantiles for men and women by educational attainment. Tables 5 and 6 show selection corrected estimation results. ${ }^{12}$

The estimated parameters inform us about the covariate impact on the wage hazard function: individual characteristics that have a negative effect on the wage hazard rate reduce the likelihood of getting a low wage. Individuals holding these characteristics are therefore more likely get a higher wage than the reference group.

Age positively and significantly affects wages only for highly educated worker. People declaring to be in good health earn higher wages, especially if men and highly educated.

\footnotetext{
${ }^{11}$ In the period from 1994 until 2001, the average real GDP growth was about $2.1 \%$, with a maximum of $3.7 \%$ in 2000 and a minimum of $1.1 \%$ in 1996 (Eurostat).

${ }^{12}$ Coefficient estimates without sample selection are not reported in the paper but available upon request.
} 
Marital status affects male wage distribution of both educational categories and the wage distribution of highly educated women. Married people earn higher wages.

Holding an atypical contractual arrangement is associated with lower wages mainly for low educated men across the overall wage distribution. The impact is milder for low educated women and it is significant at the bottom and at the top of the wage distribution. Highly educated workers of both genders with an atypical contract suffer pay penalties only at the bottom (25th quantile) of the wage distribution.

We note different impacts of the covariates for the service sector and public employment across both genders and educational categories. Low educated men and highly educated women working in the service sector or in the public administration earn higher wages.

There are geographical differences in the distribution of wages, characterized by important pay disadvantages in the Center and especially in the South of Italy. Pay disadvantages are higher for low educated women living in the Centre of Italy and located at the bottom of the wage distribution. The geographical heterogeneity is a structural feature of the Italian labour market which is not limited only to wages. For instance, Bertola and Garibaldi (2003) found evidence of geographical differences in unemployment. Sizeable geographical gaps are also found in Italian employment rates.

Longer job tenure is associated with higher wages, especially for low educated workers of both genders. High-skilled and white-collar occupations (e.g. the top first occupational category) are associated with higher wages for both genders. In terms of significance, the impact of these occupational categories is more important for low educated workers.

With regard to the remaining covariates, being employed in large firm (500 or more employees) is associated with higher wages, especially for low educated men and highly educated women. Finally, a set of time dummies is included in the model specification. These indicator variables suggest that the shape of the wage distributions of low educated men and women located at the bottom and middle of the wage distribution changed significantly since 1998.

\section{Simulations}

\subsection{Goodness-of-Fit}

In this Section, we decompose the sample selection corrected gender wage gaps into the component due to different distribution in individual characteristics and the component due to different remuneration of the same characteristics. The decomposition is carried out on the basis of microsimulations. Their reliability depends however on the ability of the wage 


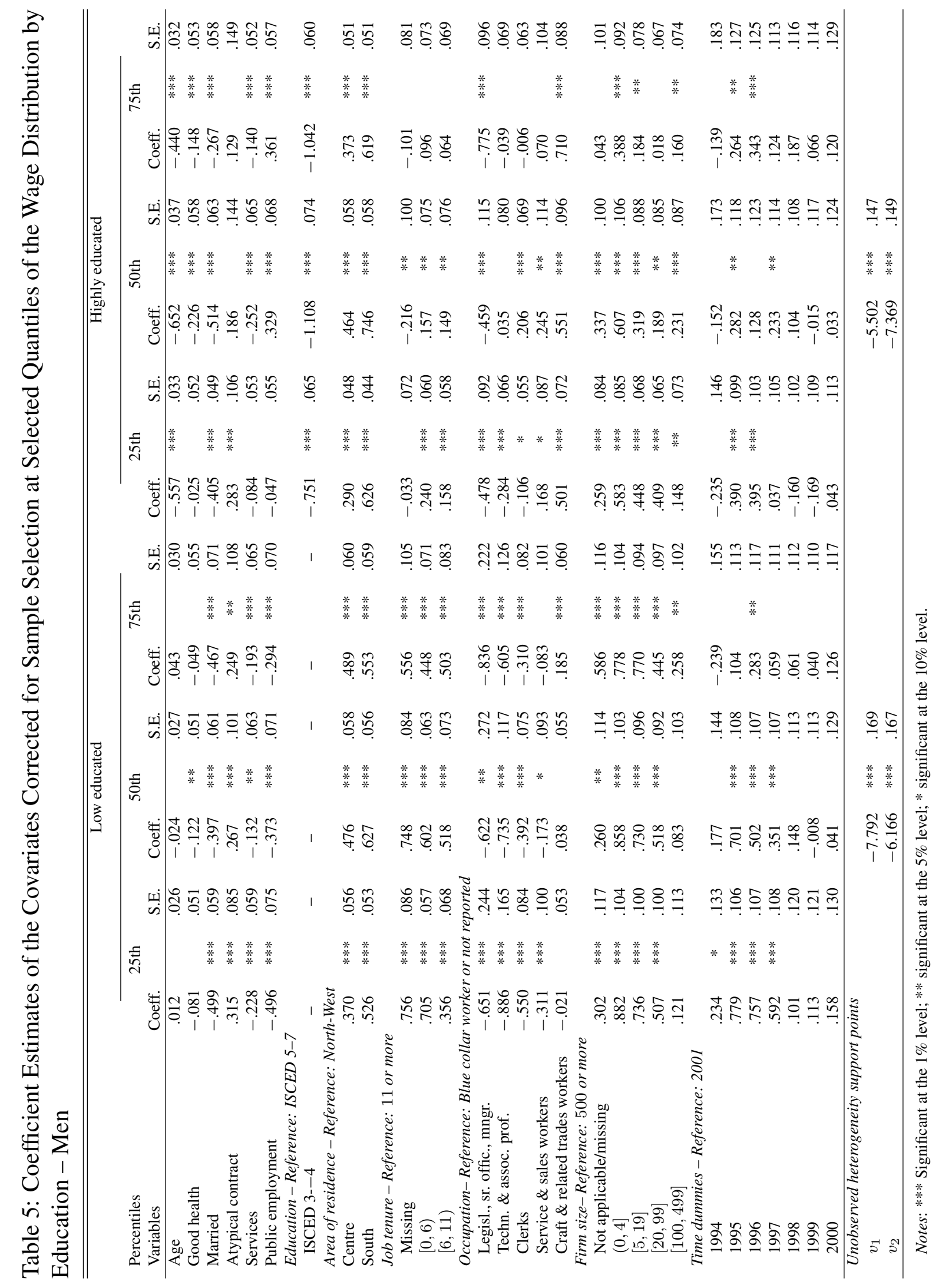




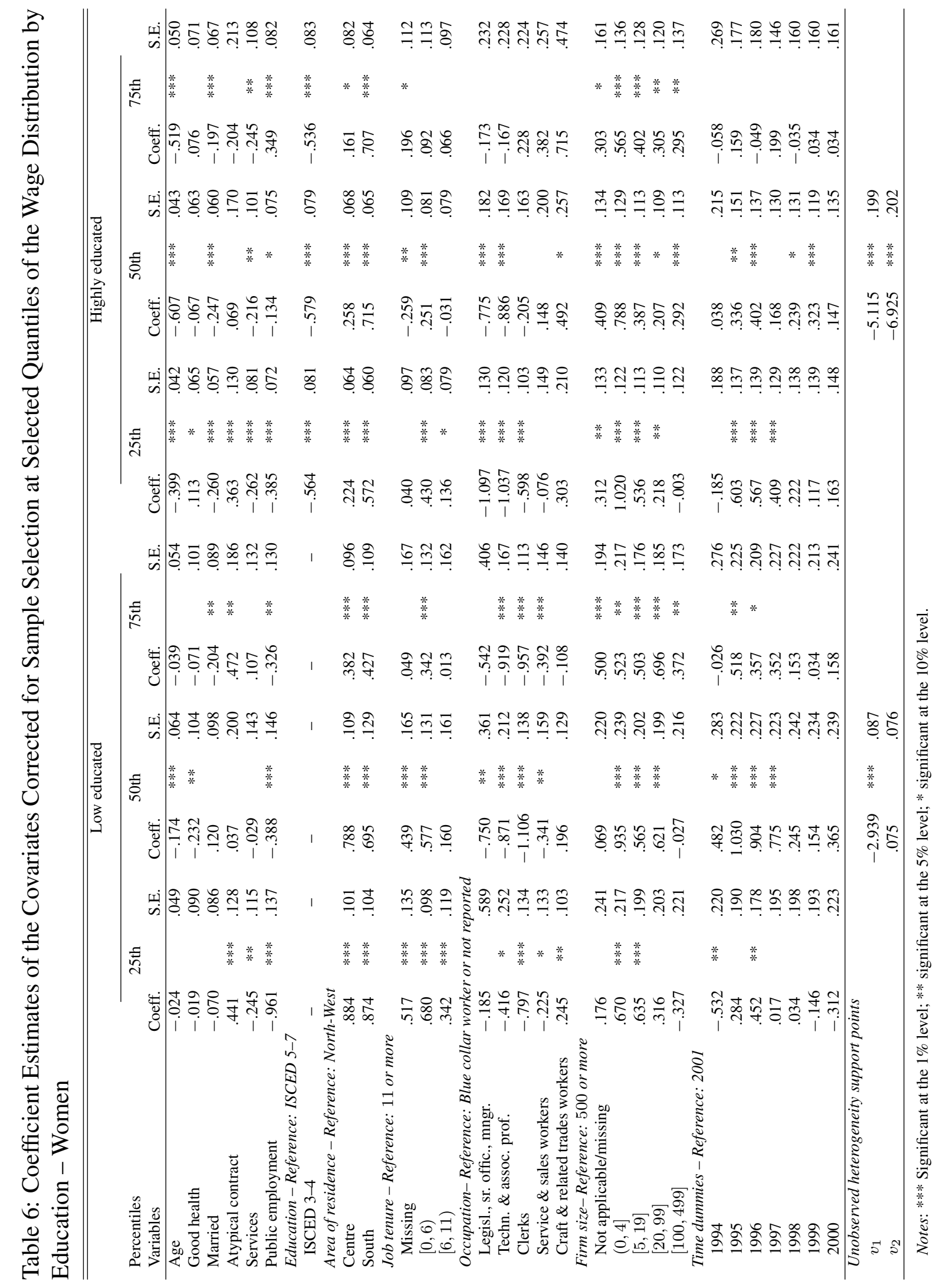


hazard function models to predict the sample selection corrected wage distributions. Hence, we first report goodness-of-fit checks of the estimated models.

The goodness-of-fit statistics are constructed on the basis of 999 simulations of fulltime employment participations and wage realizations for each individual in the sample by gender and educational attainment. At each simulation, we draw the vector of parameter estimates assuming that the estimator is Normally distributed around the point estimates with a variance-covariance matrix equal to the estimated one. This allows us to construct Monte Carlo 95\% confidence intervals around the predicted statistics and check, thereby, whether the actual statistics lie in the $95 \%$ confidence intervals of the simulated ones. ${ }^{13}$

Table 7 displays the goodness-of-fit with respect to full-time workforce participation. ${ }^{14}$ The model fits extremely well the observed full-time employment rates. The actual frequencies always lie in the $95 \%$ confidence interval of the simulated ones. The misalignment is very small and the estimated models tend to marginally underpredict the full-time work participation.

Table 7: Goodness-of-Fit of Full-Time Workforce Participation

\begin{tabular}{lcclc}
\hline \hline & Actual & Simulated & \multicolumn{2}{c}{$95 \%$ confidence interval $^{\S}$} \\
\hline Highly educated men & 0.708 & 0.697 & 0.677 & 0.718 \\
Highly educated women & 0.383 & 0.369 & 0.347 & 0.392 \\
Low educated men & 0.576 & 0.563 & 0.544 & 0.583 \\
Low educated women & 0.156 & 0.151 & 0.136 & 0.166 \\
\hline \multirow{2}{*}{ \$ Monte Carlo confidence intervals computed by 999 replications. }
\end{tabular}

Figure 2 reports the goodness-of-fit with respect to gender wage gaps by educational attainment. The model performs very well in predicting gender wage gaps for highly educated full-time workers, but it shows some systematic overprediction of the gender wage gap of low educated women. The size of the misalignment is not however large and the actual gender wage gap lies into the $95 \%$ confidence interval of the simulated one at each quantile of the wage distribution.

\subsection{Decomposition of the Gender Wage Gaps}

We exploit the simulation algorithm developed in Picchio and Mussida (2011) to decompose the sample selection corrected gender wage gaps of low and highly educated people into two

\footnotetext{
${ }^{13}$ We follow the simulation algorithm described in Picchio and Mussida (2011, Appendix A.3).

${ }^{14} \mathrm{An}$ individual is predicted to be full-time at work if the corresponding predicted propensity of full-time employment is bigger than a random number drawn from the standard uniform distribution.
} 
Figure 2: Goodness-of-Fit of The Gender Wage Gap


Note: The grey areas are Monte Carlo 95\% confidence intervals, computed by 999 replications. 
components: the one due to gender differences in the distribution of individual characteristics and the one due to gender differences in the remunerations of the same characteristics. This is in the same spirit as Oaxaca's (1973) decomposition of effects on mean wages, but we carry it out over the entire wage distribution.

The idea of the decomposition is based on recovering the counterfactual distribution that would prevail if men had the same distribution of characteristics as women. We define as $Q(\cdot)$ the log-quantile function and decompose the gender wage gap at each quantile $q \in$ $[0,100]$ of the wage distribution as follows

$$
\begin{aligned}
Q\left(q \mid \widehat{\Theta}_{M}, x_{M}\right)- & Q\left(q \mid \widehat{\Theta}_{F}, x_{F}\right)= \\
& {\left[Q\left(q \mid \widehat{\Theta}_{M}, x_{M}\right)-Q\left(q \mid \widehat{\Theta}_{M}, x_{F}\right)\right]+\left[Q\left(q \mid \widehat{\Theta}_{M}, x_{F}\right)-Q\left(q \mid \widehat{\Theta}_{F}, x_{F}\right)\right] }
\end{aligned}
$$

where, for $G \in\{F, M\}, \widehat{\Theta}_{G}$ is the set of estimated coefficients of the wage structure and $x_{G}$ is the set of individual characteristics. On the right-hand side of (3), the first term in brackets is the gender wage gap (difference in log points) at quantile $q$ if men and women were equally paid for their own characteristics. In other words, it is the component of the gender wage gap explained by gender differences in the distribution of individual characteristics. The second term in brackets is the gender wage gap at quantile $q$ if men and women had the same characteristics but they were paid differently, i.e. the part explained by different coefficients. The latter component of the gender wage gap is of special interest and it is derived by fixing observed characteristics at the female level. In Subsection 4.3, we explore the robustness of the decomposition by fixing the observed characteristics at the male level.

The decomposition is separately computed for low and highly educated people. Figures 3 and 4 show the decompositions of the gender wage gaps respectively without and with selection correction across the support of the wage distribution. They display the gender wage gap from the raw data, the one predicted by the model (left-hand side of Equation (3)), and the one if men and women had the same characteristics (second term in brackets of the right-hand side of Equation (3)). Figure 5 displays the change in the component of the gender wage gap due to different remuneration of the same characteristics when sample selection is corrected for. It helps to understand the relevance of correcting for sample selection at different percentiles of the wage distribution and at different educational levels. Table 8 summarizes point estimates of the gender wage gap due to different returns at selected quantiles of the wage distribution by education.

Figures 3 and 4 show that if men and women had the same characteristics women would suffer significant and large wage penalties, independently on whether we correct for nonrandom selection into full-time employment and on educational levels. The wage penalty is much larger for low educated women, especially after correction for sample selection: it 
ranges from $0.30 \log$ points at the bottom of the wage distribution to $0.21 \log$ points at the top of the wage distribution. For highly educated women, the wage penalty is left almost unchanged by the sample selection correction and it goes from $0.09 \log$ points at the bottom to $0.19 \log$ points at top of the wage distribution.

Figure 3: Decomposition of the Gender Wage Gap (in log points) without Sample Selection Correction
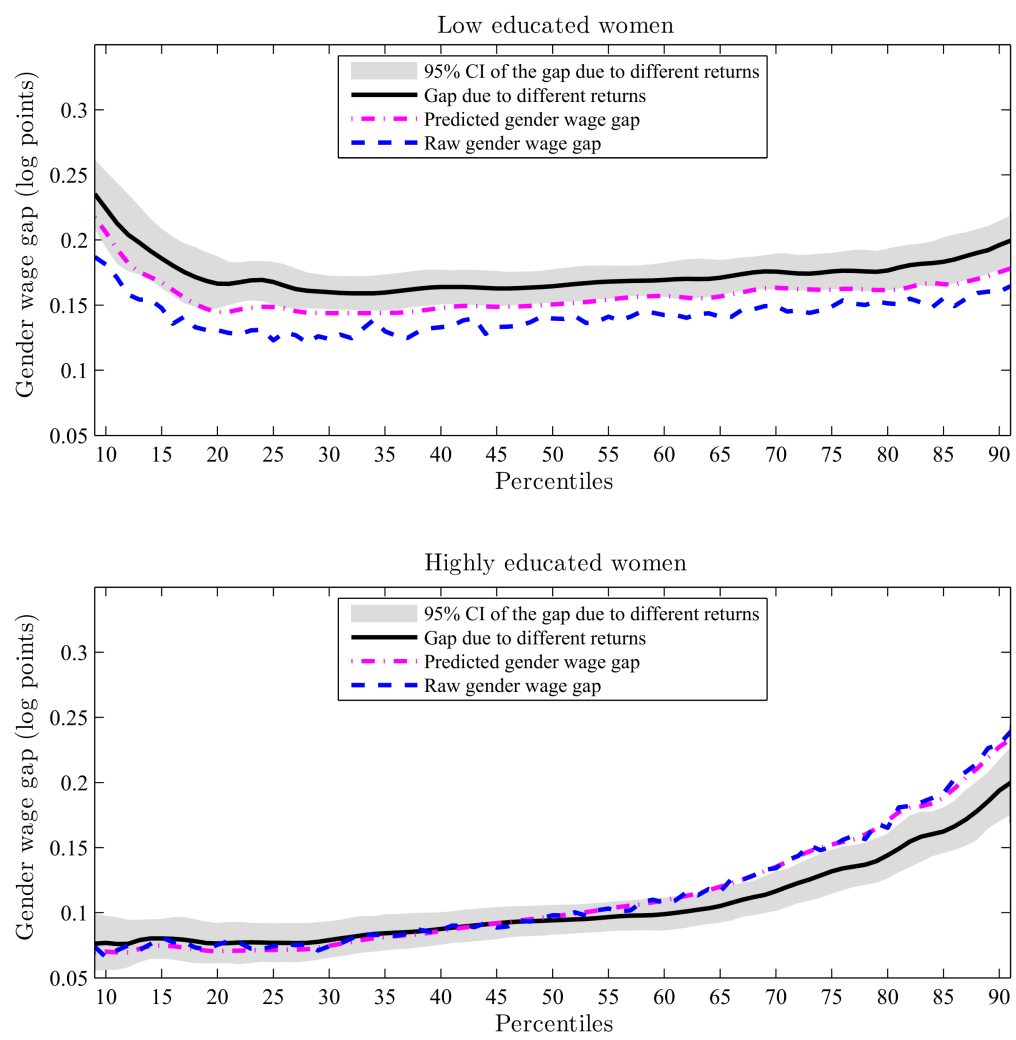

Note: The grey areas are Monte Carlo $95 \%$ confidence intervals, computed by 999 replications.

Two interesting pieces of evidence emerge from these empirical findings. First, the wage penalty of low educated women largely increases when we correct for nonrandom selection into full-time employment, especially at bottom jobs. This means that low educated women at the bottom of the wage distribution are more positively selected into full-time employment than comparable men, i.e. those low educated women who would get the lowest returns from working full-time are less likely to work full-time than comparable men. In contrast, the pay penalties are left almost unchanged for highly educated women when we control for sample selection. It is therefore important to net out the effect induced by sample selection to avoid the underestimation of the role played by education in shaping labour market inequalities. 
Figure 4: Decomposition of the Gender Wage Gap (in log points) with Sample Selection Correction
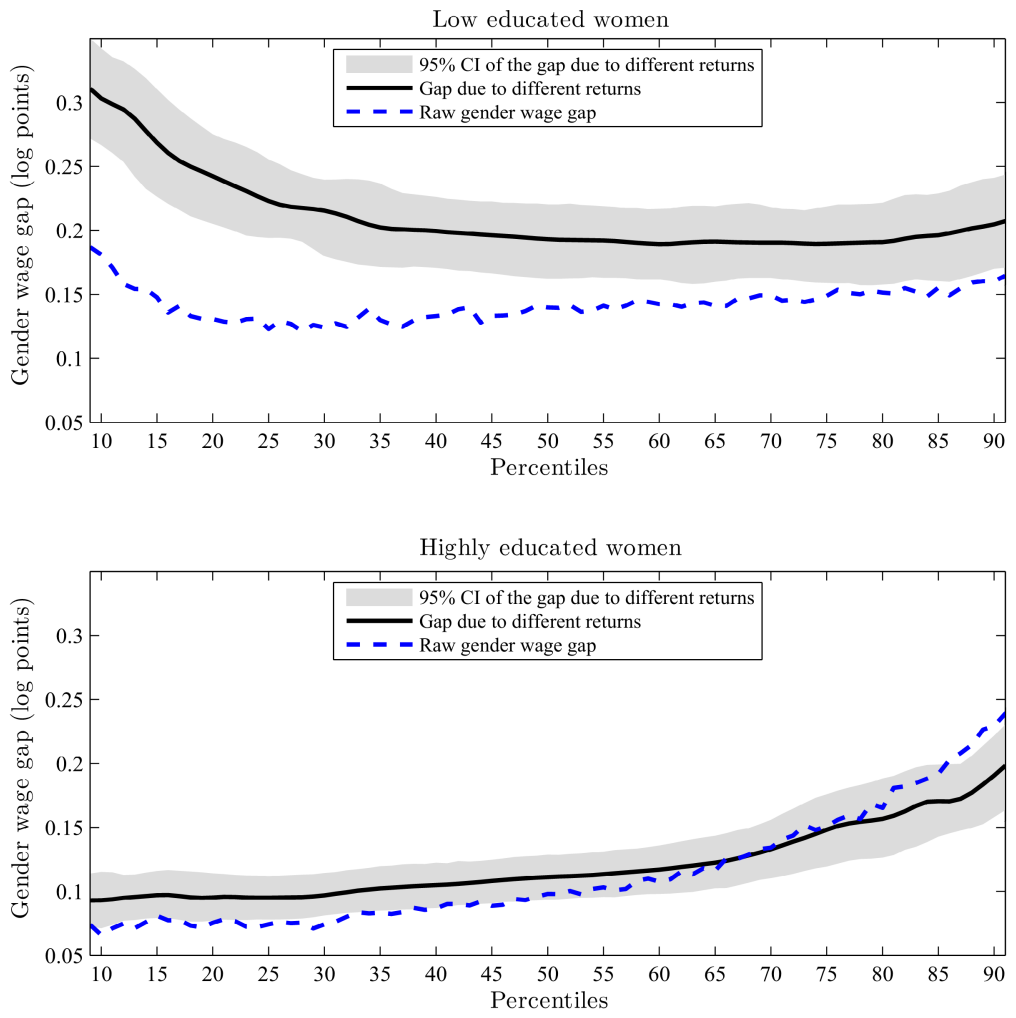

Note: The grey areas are Monte Carlo 95\% confidence intervals, computed by 999 replications. 
Figure 5: Change in the Gender Wage Gap due to Different Returns if Corrected for Sample Selection (in log points)
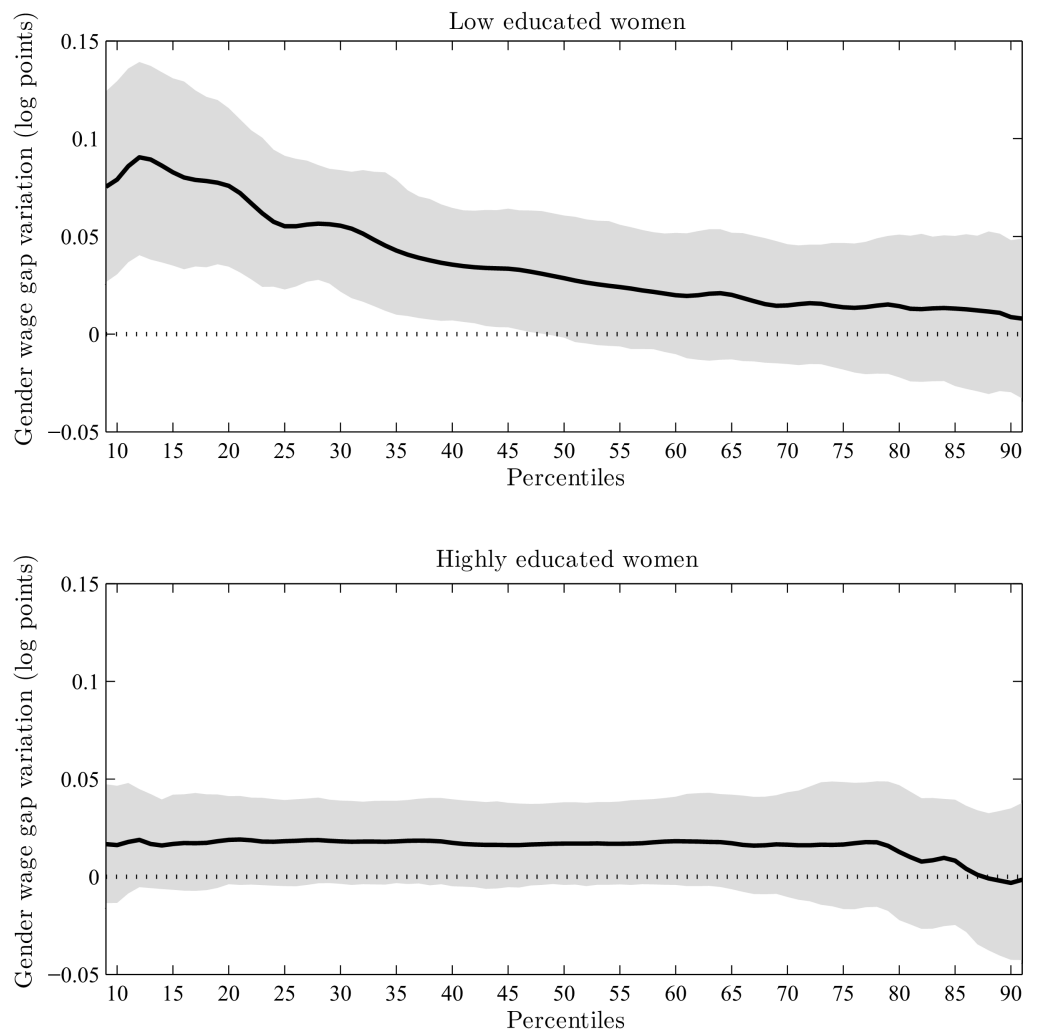

Note: The grey areas are Monte Carlo 95\% confidence intervals, computed by 999 replications. 
Table 8: Gender Wage Gap (in log points) due to Different Returns at Selected Quantiles by Education

\begin{tabular}{|c|c|c|c|c|c|c|}
\hline \multirow[b]{2}{*}{ Quantile $q$} & \multicolumn{3}{|c|}{ Low educated women } & \multicolumn{3}{|c|}{ Highly educated women } \\
\hline & $\begin{array}{l}\text { Gender wage gap } \\
\text { due to different } \\
\text { returns (log points) }\end{array}$ & $95 \%$ cor & ce interval ${ }^{\S}$ & $\begin{array}{l}\text { Gender wage gap } \\
\text { due to different } \\
\text { returns (log points) }\end{array}$ & $95 \% \mathrm{cc}$ & ce interval ${ }^{\S}$ \\
\hline & \multicolumn{6}{|c|}{ Without sample selection correction } \\
\hline 10 & .224 & .194 & .253 & .077 & .056 & .098 \\
\hline 25 & .168 & .151 & .183 & .077 & .062 & .092 \\
\hline 50 & .164 & .152 & .177 & .094 & .083 & .106 \\
\hline 75 & .176 & .162 & .190 & .132 & .115 & .148 \\
\hline \multirow[t]{2}{*}{90} & .196 & .177 & .215 & .194 & .170 & .218 \\
\hline & \multicolumn{6}{|c|}{ With sample selection correction } \\
\hline 10 & .303 & .267 & .342 & .093 & .071 & .115 \\
\hline 25 & .223 & .194 & .255 & .095 & .078 & .112 \\
\hline 50 & .193 & .162 & .220 & .111 & .093 & .129 \\
\hline 75 & .190 & .159 & .219 & .148 & .119 & .176 \\
\hline \multirow[t]{2}{*}{90} & .205 & .170 & .241 & .191 & .158 & .222 \\
\hline & \multicolumn{6}{|c|}{ Change when corrected for sample selection } \\
\hline 10 & .079 & .031 & .130 & .016 & -.014 & .047 \\
\hline 25 & .055 & .023 & .091 & .018 & -.005 & .039 \\
\hline 50 & .029 & -.002 & .061 & .017 & -.004 & .038 \\
\hline 75 & .014 & -.018 & .047 & .017 & -.017 & .048 \\
\hline 90 & .009 & -.030 & .048 & -.003 & -.043 & .035 \\
\hline
\end{tabular}

$\S$ Monte Carlo confidence intervals computed by 999 replications.

As a matter of fact, although our sample is similar to that used by Addabbo and Favaro (2011), we find that the role played by the educational level is much more relevant than the one in Addabbo and Favaro (2011), who did not take into account that gender differences in the propensity to work full-time are heterogeneous across educational levels.

Second, for low educated women there is a clear evidence of "sticky floor" after controlling for sample selection, i.e. larger gender pay gap at the bottom of the wage distribution. For highly educated women, the evidence of "glass ceiling", i.e. larger gender pay gap at the top of the wage distribution, is instead left unchanged by the sample selection correction. ${ }^{15}$

In what follows, we provide explanations on why we find that low educated women are more positively selected into full-time employment and why this is especially the case at the bottom of the wage distribution, generating sticky floors. Our explanations are not exhaustive and there might be other explanations and factors at work.

The first explanation involves discrimination. Those women who would be located at bottom jobs might decide not to participate in the workforce because discriminatory practices or occupational segregation might be stronger at bottom jobs. ${ }^{16}$ Women, especially

\footnotetext{
${ }^{15}$ The sticky floor and the glass ceiling follow the definitions in Booth et al. (2003) and Albrecht et al. (2003).

${ }^{16}$ See Blau and Khan (2006) about the relevance of discrimination on the gender pay gap.
} 
if low educated, are indeed frequently segregated in occupations characterized by a low degree of responsibility and therefore associated to lower remuneration. Indeed, Bayard et al. (2003) and Addabbo and Favaro (2011) suggest that female segregation into certain occupations might account for a sizeable fraction of the wage gap.

Another explanation hinges on gender differences in the workforce attachment and, thereby, in the propensity to participate to the labour market. Indeed, low educated women who would be located at bottom jobs might exhibit a lower workforce attachment compared to men of the same educational category. For instance, those women might decide not to participate in the workforce for preferences-related issues, i.e. they give a higher value to leisure with respect to working time.

Finally, low educated women at bottom jobs might suffer of monopsonistic wage discrimination as their labour supply might be less elastic than the one of comparable men (Boal and Ramson, 1997). Hirsch et al. (2010) find indeed that the labour supply to the firm is less elastic for women than for men and suggest as potential explanations different preferences over nonwage job characteristics and a lower degree of the female mobility. For example, female job mobility might be less determined by wages and by the state of the local labour market and more influenced by the job proximity to home and/or a nursery or by the flexibility of the working time. This might be especially true for low educated women at bottom jobs, since the family budget constraints are more likely to be binding and family child care is more likely to be the only affordable option. Firms can take advantage of these gender differences in supply elasticities and in the degree of monopsony power, resulting thereby in wage penalties for low educated women at bottom jobs.

\subsection{Robustness Analyses}

We run sensitivity analyses to check whether the estimation results are robust to four different sources of misspecification. Firstly, we re-estimated the model without exclusion restrictions. Picchio and Mussida (2011) show that identification is attained through withinperson replication and without the need of exclusion restrictions. However, in the empirical analysis we exploited exclusion restrictions. Hence, by presenting the results without exclusion restrictions we can explore the sensitivity of our results to the imposed overidentifying restrictions.

Secondly, we redid the decomposition exercise by using the male population as the population of reference. By simulating the counterfactual wage distribution if men were paid as 
women, we can alternatively decompose the gender wage gap as follows:

$$
\begin{aligned}
Q\left(q \mid \widehat{\Theta}_{M}, x_{M}\right)- & Q\left(q \mid \widehat{\Theta}_{F}, x_{F}\right)= \\
& {\left[Q\left(q \mid \widehat{\Theta}_{M}, x_{M}\right)-Q\left(q \mid \widehat{\Theta}_{F}, x_{M}\right)\right]+\left[Q\left(q \mid \widehat{\Theta}_{F}, x_{M}\right)-Q\left(q \mid \widehat{\Theta}_{F}, x_{F}\right)\right] . }
\end{aligned}
$$

On the right-hand side, the first term in brackets is the wage gap due to gender differences in the remuneration of the same characteristics, where the characteristics are fixed at the male level. In the benchmark decomposition, we instead simulated the counterfactual wage distribution if women were paid as men and therefore we evaluated the wage gap due to gender differences in the remuneration of the same characteristics, where the characteristics were fixed at the female level.

Thirdly, we re-estimated the model by assuming that the idiosyncratic error term of the full-time employment equation has a Logistic distribution instead of a Gompertz distribution. We check thereby whether the results are robust to the imposed assumption on the error term of the probability model for working full-time.

Lastly, we checked the sensitivity of our results to the imposed discrete distribution of the unobserved determinants. We increased the number of points of support to three for each process, resulting in nine probability masses defined as follows:

$$
\begin{array}{ll}
p_{1} \equiv \operatorname{Pr}\left(v=v_{1}, \varepsilon=\varepsilon_{1}\right) & p_{2} \equiv \operatorname{Pr}\left(v=v_{2}, \varepsilon=\varepsilon_{1}\right) \\
p_{3} \equiv \operatorname{Pr}\left(v=v_{1}, \varepsilon=\varepsilon_{2}\right) & p_{4} \equiv \operatorname{Pr}\left(v=v_{2}, \varepsilon=\varepsilon_{2}\right) \\
p_{5} \equiv \operatorname{Pr}\left(v=v_{1}, \varepsilon=\varepsilon_{3}\right) & p_{6} \equiv \operatorname{Pr}\left(v=v_{3}, \varepsilon=\varepsilon_{1}\right) \\
p_{7} \equiv \operatorname{Pr}\left(v=v_{2}, \varepsilon=\varepsilon_{3}\right) & p_{8} \equiv \operatorname{Pr}\left(v=v_{3}, \varepsilon=\varepsilon_{2}\right) \\
p_{9} \equiv \operatorname{Pr}\left(v=v_{3}, \varepsilon=\varepsilon_{3}\right)=1-\sum_{r=1}^{8} p_{r} .
\end{array}
$$

In this case, we need to estimate six points of support and eight probability masses.

The gender wage gap decompositions at selected percentiles corresponding to these four sensitivity checks are reported in Table $9 .{ }^{17}$ All four sensitivity analyses return gender wage gap decompositions which are very much in line with those from the benchmark specification. They assess thereby the robustness of our empirical findings.

\footnotetext{
${ }^{17}$ The decompositions at each percentile and the full set of estimation results on which the gender wage decompositions in Table 9 are computed are not reported for the sake of brevity but they are available upon request.
} 
Table 9: Sensitivity Analyses

\begin{tabular}{|c|c|c|c|c|c|c|}
\hline \multirow[b]{2}{*}{ Quantile $q$} & \multicolumn{3}{|c|}{ Low educated women } & \multicolumn{3}{|c|}{ Highly educated women } \\
\hline & $\begin{array}{l}\text { Gender wage gap } \\
\text { due to different } \\
\text { returns (log points) }\end{array}$ & $95 \%$ & nce interval ${ }^{\S}$ & $\begin{array}{l}\text { Gender wage gap } \\
\text { due to different } \\
\text { returns (log points) }\end{array}$ & $95 \%$ & nce interval ${ }^{\S}$ \\
\hline \multicolumn{7}{|c|}{ 1. Without exclusion restrictions } \\
\hline 10 & .306 & .270 & .342 & .095 & .072 & .119 \\
\hline 25 & .226 & .196 & .258 & .097 & .079 & .114 \\
\hline 50 & .196 & .167 & .223 & .112 & .095 & .129 \\
\hline 75 & .192 & .164 & .220 & .150 & .124 & .176 \\
\hline 90 & .207 & .175 & .240 & .192 & .160 & .226 \\
\hline \multicolumn{7}{|c|}{ 2. Men as population of reference } \\
\hline 10 & .300 & .264 & .339 & .092 & .068 & .116 \\
\hline 25 & .220 & .190 & .255 & .099 & .077 & .119 \\
\hline 50 & .193 & .165 & .222 & .124 & .103 & .143 \\
\hline 75 & .194 & .166 & .222 & .164 & .131 & .195 \\
\hline 90 & .209 & .173 & .249 & .201 & .166 & .241 \\
\hline \multicolumn{7}{|c|}{ 3. Logit model for full-time employment } \\
\hline 10 & .306 & .270 & .344 & .094 & .071 & .117 \\
\hline 25 & .225 & .197 & .256 & .096 & .078 & .114 \\
\hline 50 & .195 & .165 & .222 & .111 & .092 & .129 \\
\hline 75 & .191 & .162 & .219 & .147 & .117 & .176 \\
\hline 90 & .206 & .172 & .242 & .190 & .156 & .222 \\
\hline \multicolumn{7}{|c|}{ 4. Unobserved heterogeneity distribution with 3 support points and 9 probability masses } \\
\hline 10 & .264 & .198 & .342 & .108 & .079 & .140 \\
\hline 25 & .194 & .146 & .259 & .106 & .079 & .134 \\
\hline 50 & .167 & .118 & .217 & .128 & .102 & .157 \\
\hline 75 & .161 & .111 & .207 & .164 & .122 & .200 \\
\hline 90 & .165 & .107 & .217 & .195 & .139 & .240 \\
\hline
\end{tabular}

$\S$ Monte Carlo confidence intervals computed by 999 replications. 


\section{Conclusions}

In most industrialized countries, the gender wage gaps decreased in the last decades mainly for the increased level of education and work experience of women. However, if one nets out the contribution of gender differences in individual characteristics, the gender wage gaps have been roughly constant over the decades. In order to design effective policies in tackling gender inequalities it is important to understand whether and to what extent the gender pay gaps are due to gender differences in the distribution of personal characteristics or in the rewards of the same characteristics.

In this article, we analysed the gender wage gaps in Italy at different educational levels. Education might indeed play a relevant role in shaping the gender pay gap. The European Commission (2005) reports that education is the most important observed characteristic explaining the wage inequality between men and women.

The empirical analysis exploited the estimator of probability density functions in the presence of covariates and sample selection proposed by Picchio and Mussida (2011) and microsimulation to decompose the gender wage gap. We decomposed the gender wage gap at each quantile of the wage distribution into a part due to different coefficients determining the wage structure and a part due to different individual characteristics. The empirical analysis was based on 1994-2001 ECHP data.

Two interesting findings emerged from our study. First, if men and women had the same characteristics women would suffer significant and large pay penalties, independently on whether we correct for nonrandom selection into full-time employment and on educational levels. Second, low educated women suffer much larger pay penalties, especially after correcting for sample selection and at the bottom of the wage distribution. More in detail, when we controlled for nonrandom sample selection, we found a more marked evidence of "sticky floor" for low educated women and an unchanged evidence of "glass ceiling" for highly educated women. This means that low educated women are, relatively to men, more positively selected into the full-time workforce than at high educational levels.

Our findings therefore suggest that in order to reduce gender wage gaps in Italy, it is important to focus on low educated women, especially at bottom jobs. We suggested possible explanations consistent with our findings. First, low educated women might suffer more from discrimination and occupational segregation. Second, low educated women might be less attached to the labour market than low educated men, since they might give a higher value to leisure. Lastly, low educated women might suffer from monopsonistic wage discrimination, as women might have different preferences over nonwage job characteristics and a lower degree of mobility than comparable men. 


\section{References}

Addabbo, T. and D. Favaro, "Gender Wage Differentials by Education in Italy," Applied Economics, 2011, 43 (29), 4589-4605.

Albrecht, J., A. Bjorklund, and S. Vroman, "Is There a Glass Ceiling in Sweden?," Labour Economics, 2003, 21 (1), 145-177.

_, A. van Vuuren, and S. Vroman, "Counterfactual Distributions with Sample Selection Adjustments: Econometric Theory and an Application to the Netherlands," Labour Economics, 2009, 16 (4), 383-396.

Azmat, G., M. Güell, and A. Manning, "Gender Gaps in Unemployment Rates in OECD Countries," Journal of Labor Economics, 2006, 24 (1), 1-37.

Bayard, K., J. Hellerstein, D. Neumark, and K. Troske, "New Evidence on Sex Segregation and Sex Differences in Wages from Matched Employee-Employer Data," Journal of Labor Economics, 2003, 21 (4), 887-922.

Bertola, G. and P. Garibaldi, "The Structure and History of Italian Unemployment," 2003. CESifo Working Paper Series No. 907, Munich.

Bettio, F. and A. Verashchagina, "Gender Segregation in the Labour Market: Root Causes, Implications and Policy Responses in Italy," 2008. External report commissioned by and presented to the EU DirectorateGeneral Employment and Social Affairs, Unit G1 "Equality between Women and Men".

Blau, F.D. and L.M. Khan, "The Gender Pay Gap in the 1990s: Slowing Convergence," Industrial and Labor Relations Review, 2006, 60 (1), 45-66.

Boal, W.M. and M.R. Ramson, "Monopsony in the Labor Market," Journal of Economic Literature, 1997, $35(1), 86-112$.

Booth, A.L., M. Francesconi, and J. Frank, "A Sticky Floors Model for Promotion, Pay, and Gender," European Economic Review, 2003, 47 (2), 295-322.

de la Rica, S., J.J. Dolado, and V. Llorens, "Ceiling or Floors? Gender Wage Gaps by Education in Spain," Journal of Population Economics, 2008, 21 (3), 751-776.

Donald, S.G., D.A. Green, and H.J. Paarsch, "Differences in Wage Distributions between Canada and the United States: An Application of a Flexible Estimator of Distribution Functions in the Presence of Covariates," Review of Economic Studies, 2000, 67 (4), 609-633.

European Commission, "Employment in Europe 2005: Recent Trends and Prospects," International Publications, 2005, Paper 34.

Gerber, T.P. and S.Y. Cheung, "Horizontal Stratification in Postsecondary Education: Forms, Explanations, and Implications," Annual Review of Sociology, 2008, 34, 299-318.

Heckman, J.J. and B. Singer, "A Method for Minimizing the Impact of Distributional Assumptions in Econometric Models for Duration Data," Econometrica, 1984, 52 (2), 271-320.

Hirsch, B., T. Schank, and C. Schnabel, "Differences in Labor Supply to Monopsonistic Firms and the Gender Pay Gap: An Empirical Analysis Using Linked Employer-Employee Data from Germany," Journal of Labor Economics, 2010, 28 (2), 291-330. 
Kolesnikova, N. and Y. Liu, "Gender Wage Gap May Be Much Smaller Than Most Think," The Regional Economist, October 2011. Available on line at http://stlouisfed.org/publications/pub_assets/pdf/re/2011/d/gender_wage_gap.pdf.

MIUR, L'Università in cifre 2006. Available on line at http://statistica.miur.it/normal.aspx?link=pubblicazioni.

Mussida, C. and M. Picchio, “The Trend over Time of the Gender Wage Gap in Italy,” 2011. IZA Discussion Paper No. 5932, Bonn.

Oaxaca, R., "Male-Female Differentials in Urban Labor Markets," International Economic Review, 1973, 14 (3), 673-709.

Olivetti, C. and B. Petrongolo, "Unequal Pay or Unequal Employment? A Cross-Country Analysis of Gender Gaps,” Journal of Labor Economics, 2008, 26 (4), 621-654.

Pekkarinen, T. and J. Vartiainen, "Gender Differences in Promotion on a Job Ladder: Evidence from Finnish Metalworkers," Industrial and Labor Relations Review, 2006, 59 (2), 285-301.

Picchio, M. and C. Mussida, "Gender Wage Gap: A Semi-Parametric Approach With Sample Selection Correction,” Labour Economics, 2011, 18 (5), 564-578.

Triventi, M., "Something changes, something not. Long-term trends in gender segregation of fields of study in Italy," Italian Journal of Sociology of Education, 2010, 2, 47-80.

Van den Berg, G.J. and M. Lindeboom, "Attrition in Panel Survey Data and the Estimation of Multi-State Labor Market Models," Journal of Human Resources, 1998, 33 (2), 458-478.

_ , _ , and G. Ridder, "Attrition in Longitudinal Panel Data and the Empirical Analysis of Dynamic Labour Market Behaviour,” Journal of Applied Econometrics, 1994, 9 (4), 421-435.

Weichselbaumer, D. and R. Winter-Ebmer, "A Meta-Analysis of the International Gender Wage Gap," Journal of Economic Surveys, 2005, 19 (3), 479-511. 